glucagon in small-for-dates infants rose significantly more than in the normal infants $(P<0.01)$. The infants of diabetic mothers, however, had the largest fall in blood glucose, reaching the lowest mean absolute level (see Table). The five infants of diabetics who developed a blood glucose below $20 \mathrm{mg} / 100 \mathrm{ml}$ had a mean pancreatic glucagon of $144.0 \mathrm{pg} / \mathrm{ml}$ at birth, and this rose only $16.0 \mathrm{pg}$ at two hours which was not significantly different from the group as a whole. The mean umbilical vein pancreatic glucagon level in six normal infants delivered by caesarean section was 128.3 (S.E. of mean 19.4), and in 10 infants of insulin-dependent diabetic mothers the mean level was 136.0 (S.E. of mean 19.6). These values do not differ significantly from each other or from the group as a whole.

\section{Discussion}

The conventionally accepted reason for hypoglycaemia in the neonate of a diabetic mother is excessive insulin release (Pedersen, Bojsen-Moller, and Poulsen, 1954; Baird, 1969). Insulin levels immediately after birth are certainly raised but so is the blood sugar. There is much controversy as to whether the insulin level is still inappropriately high during hypoglycaemia. Several workers have also reported that insulin release in the infants of diabetic mothers is not increased after intravenous glucose loads, nor is the glucose assimilation excessive (Isles and Farquhar, 1967; King, Adam, Clementi, and Schwartz, 1969). Therefore it is possible that hypoglycaemia is due in part or even primarily to a failure of glycogenolysis or gluconeogenesis.

The development of a sensitive microassay for pancreatic glucagon allows examination of a factor which may be of importance in this situation. Blood glucose in the infant of a diabetic has reached a nadir at about one hour after birth and then remains low for around six hours before gradually rising to more normal levels (McCann et al., 1966). The two-hour sampling time used in this study therefore encompasses the the period of maximum stimulus to glucagon release. Small-fordates infants were used as a comparison group. In general these infants develop hypoglycaemia as a consequence of nutritional depletion, and might therefore be expected to have normal hormonal responses. In fact they had a larger glucagon rise than the normal infants.
The blunted pancreatic glucagon response to severe hypoglycaemia in infants of diabetics could be explained in the following ways. Firstly, the pancreatic alpha cells of both normal neonates and the offspring of diabetic mothers may not be responsive to changes in blood glucose but controlled by other factors which are more identical. It has certainly been established that the normal neonatal beta cell has an impaired insulin response to glucose infusions (Isles, Dickson, and Farquhar, 1968). Secondly, it is possible that the alpha cell is affected by the prolonged intrauterine hyperglycaemia.

The cause of the hypoglycaemia after birth in an infant of a diabetic mother may well be multifactorial. The impairment of glucagon release is likely to be a significant component.

We would like to thank Dr. J. D. N. Nabarro and Professor C. E. Stroud for their helpful advice and manuscript corrections. Hoechst Pharmaceuticals Ltd. very kindly supplied antiserum $30 \mathrm{~K}$. This article is based on a paper delivered at the British Diabetic Association meeting in April 1972.

S.R.B. received support from the British Diabetic Association and D.I.J. was on a Maws Fellowship.

Requests for reprints should be addressed to: Dr. S. R. Bloom, Institute of Clinical Research, The Middlesex Hospital, London W.1.

\section{References}

Adam, P. A. J. (1971). Advances in Metabolic Disorders, 5, 183.

Baird, J. D. (1969). Fournal of Endocrinology, 44, 139.

Beard, A., et al. (1971). Fournal of Pediatrics, 79, 314.

Bloom, S. R. (1971). Diabetologia, 7, 472.

Cornblath, M., et al. (1961). Pediatrics, 28, 592.

Farquhar, J. W., and Isles, T. E. (1968). South African Medical fournal 42237.

Isles, T. W., Dickson, M., and Farquhar, J. W. (1968). Pediatric Research, Isles, T. E., and Farquhar, J. W. (1967). Pediatric Research, 1, 119.

King, K. C., Adam, P. A., Clementi, G. A., and Schwartz, R. (1969). Marks, V (1959), Clinica

Mcta, 4, 395.

. New England fournal of Medicine, 275, 1.

Faloona, G. R., and Unger, R. H. (1971). Fournal of Clinical Investigation, 50, 1992

Park, C. R., and Exton, J. H. (1972). In Glucagon, ed. P. J. Lefebre and R. H. Unger, p. 77. Oxford, Pergamon.

Pedersen, J., Bojsen-Moller, B., and Poulsen, H. (1954). Acta Endocrinologica' Kobenhavn), 15, 22 ,

Pildes, R., Forbes, A. E., O'Connor, S. M., and Cornblath, M. (1967) Fournal of Pediatrics, 70, 76.

Tanner, J. M., and Thomson, A. M. (1970). Archives of Disease in Childhood, $45,566$.

\title{
Haemostatic Changes during Dialysis Associated with Thrombus Formation on Dialysis Membranes
}

\author{
R. M. LINDSAY \\ C. R. M. PRENTICE, \\ J. F. DAVIDSON, \\ J. A. BURTON, \\ G. P. MCNICOL
}

British Medical fournal, 1972, 4, 454-458

\section{Summary}

Platelet counts, coagulation factors, and the fibrinolytic system were studied in seven regular dialysis patients

University Department of Medicine and the Department of Haematology, Royal Infirmary, Glasgow

R. M. LINDSAY, M.B., M.R.C.P., Senior Registrar in Medicine

C. R. M. PRENTICE, M.D., M.R.C.P., Senior Wellcome Research Fellow

J. F. DAVIDSON, M.B., M.R.C.P., Consultant Haematologist

University of Leeds

G. P. MCNICOL, M.D., F.R.C.P., Professor of Medicine (Present Address: Department of Medicine, General Infirmary, Leeds) during the course of haemodialysis by parallel flow (Gambro-Alwall) and coil (Travenol Ultra-Flo 100) dialysers. Significant falls in the patients' platelet counts and rises in their factor $V$ levels were found with both dialysis systems. The changes were more pronounced over the course of a Gambro-Alwall dialysis, when significant falls in the partial thromboplastin clotting time and in the plasminogen levels were also noted. These haemostatic changes were associated with the retention of platelets on the dialysis membranes and, in the case of the Gambro-Alwall dialyser, with the formation of plateletfibrin thrombus. This thrombus formation may take place in spite of efficient heparin anticoagulation and may cause excessive blood loss to the regular dialysis patient. 


\section{Introduction}

Haemodialysis with some types of parallel flow dialyser may be associated with a higher patient blood loss than with a coil dialyser of the same surface area. This is owing to thrombus formation on the cuprophane membranes of the dialyser (Muir et al., 1970; Lindsay et al., 1972). Such iatrogenic sources of blood loss may aggravate the anaemia of a regular dialysis patient by causing iron deficiency (Lawson et al., 1968; Hocken and Marwah, 1971) and should be avoided as blood transfusion is undesirable in these patients because of the risk of hepatitis (Brunner et al., 1972). It was important, therefore, to study the cause and extent of thrombus formation occurring on dialysis membranes in the presence of heparin. Accordingly, we have made haemostatic studies on regular dialysis patients before and after dialysis with parallel flow or coil dialysers and have analysed the thrombotic material which accumulates on the membranes during haemodialysis.

\section{Patients and Methods}

Seven regular dialysis patients (four males and three females) were studied with their agreement. Each patient was dialysed by both a parallel flow and a coil system for six to eight hours. During dialysis all patients were heparinized with an initial dose of 2,000 units and then 2,000 units per hour of dialysis to maintain the clotting time at $37^{\circ} \mathrm{C}$ in excess of 30 minutes. Each dialysis was terminated with a standard "wash-back" procedure as described previously (Muir et al., 1970; Lindsay et al., 1972) during which $100 \mathrm{mg}$ protamine sulphate (Weddel Pharmaceuticals Ltd.) was given into the dialyser "venous" line. At no time did protamine sulphate, an agent known to precipitate fibrinogen (Mylon et al., 1942), come into contact with the dialyser.

\section{DIALYSERS}

The 11-layered 1- $\mathrm{m}^{2}$ disposable parallel flow Gambro-Alwall dialyser (Ab Gambro, Lund, Sweden) contains PT 325 cuprophane membranes (J. P. Bemberg), and is shown diagrammatically in Fig. 1. The $1-\mathrm{m}^{2}$ Ultra-Flo 100 (Travenol) coil has PT 300 cuprophane membranes.

After use each dialyser was dismantled and the site and macroscopic appearance of residual blood was noted. One dialyser of each type was filled with buffered glutaraldehyde immediately after the "wash-back" procedure, and after one hour membrane specimens were taken for scanning electronmicroscopy as described by Muir et al. (1970). Other 2-cm membrane specimens were taken immediately after dialysis for immunofluorescent studies. The membrane was gently washed in $0.1 \mathrm{M}$ phosphate buffer, mounted on glass microscope slides, and flooded with $0.5 \mathrm{ml}$ fluorescein isothiocyanate conjugated rabbit antihuman fibrinogen (Hoechst Pharmaceuticals Ltd.), and incubated at room temperature in a moist Petri dish for 30 minutes. Unfixed antisera was then removed by washing in $0.1 \mathrm{M}$ phosphate buffer, and the specimen was mounted in glycerol saline under a glass coverslip. Specimens were examined by phase contrast, incident fluorescence, and combined phase fluorescence in a Leitz ortholux microscope.

\section{HAEMOSTATIC INVESTIGATIONS}

Venous blood was taken in plastic syringes, with the minimum of venous occlusion, at the start of dialysis and again at five minutes after protamine sulphate had been given at the end of dialysis. Blood was mixed with one-tenth of the total volume $3.8 \%$ sodium citrate. It was kept at $4{ }^{\circ} \mathrm{C}$ for coagulation, and at $20^{\circ} \mathrm{C}$ for platelet studies. A $5-\mathrm{ml}$ sample was allowed to clot in a tube containing glass beads and $1 \mathrm{mg}$ tranexamic acid for assay of fibrin-fibrinogen degradation products.
Platelet counts (Dacie and Lewis, 1970a) were carried out on citrated whole blood and on platelet-rich plasma prepared by centrifugation at $400 \mathrm{~g}$ for five minutes at room temperature. Platelet factor III availability was estimated by the method of Hardisty and Hutton (1965). The coagulation tests performed were thrombin clotting time (McNicol and Douglas, 1964), onestage prothrombin time (Douglas, 1964), kaolin-cephalin clotting time (Proctor and Rapaport, 1961), and the partial thromboplastin time (Langdell et al., 1963). The plasma recalcification time was measured in a plastic tube by mixing $0.1 \mathrm{ml}$ of $0.15 \mathrm{M}$ saline and $0.1 \mathrm{ml}$ of fresh non-contacted plasma at $37^{\circ} \mathrm{C}$, adding $0.1 \mathrm{ml}$ of $0.025 \mathrm{M}$ calcium chloride, and recording the clotting time. Assays were carried out of factor V (Shanberge et al., 1967), factor VIII (Breckenridge and Ratnoff, 1962), and fibrinogen (Ratnoff and Menzie, 1964). Tests of fibrinolysis were plasminogen (Remmert and Conen, 1949), euglobulin lysis-time (Nilsson and Olow, 1962), and assay of serum fibrin-fibrinogen degradation products (Merskey et al., 1966). The urokinase-sensitivity test was performed as described by McNicol et al., (1965).

\section{RADIOCHROMIUM PLATELET STUDY}

In this separate study each of five regular dialysis patients underwent plasmaphoresis, and the platelets from $430 \mathrm{ml}$ whole blood were obtained and labelled with radiochromium using $200 \mu \mathrm{Ci}$ ${ }^{51} \mathrm{Cr}$ by the method of Dacie and Lewis (1970b). The labelled platelets were returned to each patient who two days later underwent an eight-hour dialysis using a Gambro-Alwall dialyser. At the start of dialysis a $100-\mathrm{ml}$ whole blood sample was taken. A $20-\mathrm{ml}$ subsample of this was divided by centrifugation at $450 \mathrm{~g}$ for five minutes and then at $1,500 \mathrm{~g}$ for 30 minutes at $18^{\circ} \mathrm{C}$ into platelet-rich plasma, platelet-poor plasma, and packed red cells. The latter were washed and then made up to a $10-\mathrm{ml}$ volume using $0 \cdot 15 \mathrm{M}$ saline. The platelet-rich and platelet-poor plasma samples were also made up to $10-\mathrm{ml}$ volumes using $0 \cdot 15 \mathrm{M}$ saline. The three samples were then counted in identical geometries using a scintillation counter to study the distribution of the isotope. On each occasion over $90 \%$ of the radioactivity was present in the platelet-rich plasma. After each dialysis the dialyser was dismantled and the membranes were placed in 4litre cans which were filled with tap-water, sealed, and their radioactivity was counted in a large well scintillation counter. A standard was prepared on each occasion by taking the plateletrich plasma frorn the remaining $80 \mathrm{ml}$ of whole blood and estimating the total number of platelets in the sample. This standard was then placed in a 4-litre can, which was handled identically to the can containing the dialysis membranes. By comparing the radioactivity of each can an estimate of the numbers of platelets retained by the membranes was made. In doing this it was assumed that the ${ }^{51} \mathrm{Cr}$-labelled platelets behaved identically to unlabelled platelets. This method is similar to that used for the estimation of the dialyser residual blood volume (Muir et al., 1970; Lindsay et al., 1972). The estimated number of platelets on the dialysis membranes was compared with the expected platelet loss, assuming that platelets would be lost only according to their concentration in whole blood. To do this the predialysis platelet count was estimated, and the blood loss per dialysis was assumed to be $36 \mathrm{ml}$ - a figure based on previous experiments (Lindsay et al., 1972).

\section{Results}

Dialyser Appearance and Membrane Studies.-On dismantling each Gambro-Alwall dialyser variable amounts of blood were seen, especially towards the "venous" and "outlet" end of each membrane compartment (Fig. 1). The material had the macroscopic appearance of thrombus and was fairly adherent to the dialysis membrane. Scanning electronmicroscopy showed platelets and fibrin-like strands trapping red blood cells (Fig. 2) on the membrane. Immunofluorescent studies with antihuman 
fibrinogen showed fibrin-positive material to be present on the membrane in the form of strands (Fig. 3). When each coil dialyser was dismantled small amounts of blood were found mainly at the junctions of the blood lines and the membrane tubing. This blood was easily washed away and did not resemble thrombus. Scanning electronmicroscopy showed platelets and few fibrin-like strands but these were much less evident than those seen on the membranes of the Gambro-Alwall dialyser. By immunofluorescence a few strands could be shown to react with antifibrinogen serum.

Platelet Studies. - The platelet counts before and after dialysis are shown in Fig. 4. A constant and significant fall in platelet count over the dialysis period was shown for both dialysers (Travenol $P<0.02$; Gambro $P<0.01$ ). The mean percentage fall of platelets after dialysis with the Gambro dialyser was

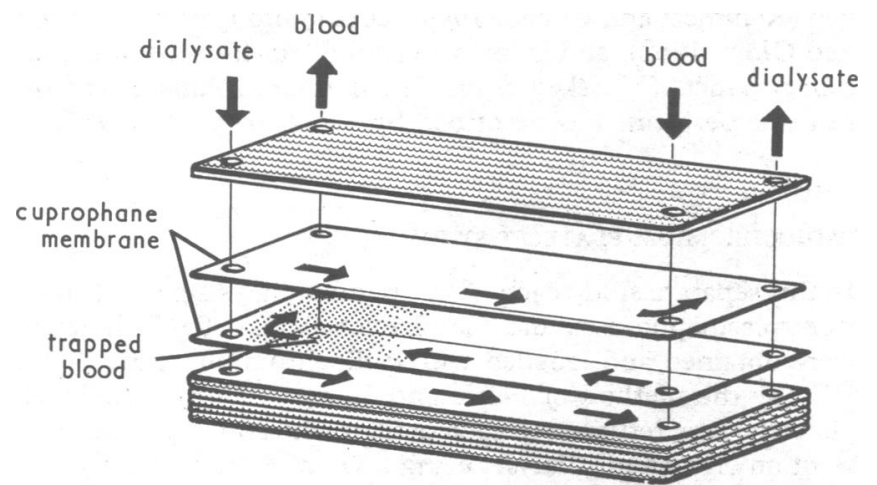

FIG. 1-Exploded diagram of the 11-layered Gambro-Alwall dialyser. Stippled area indicates the site of maximum thrombus formation.

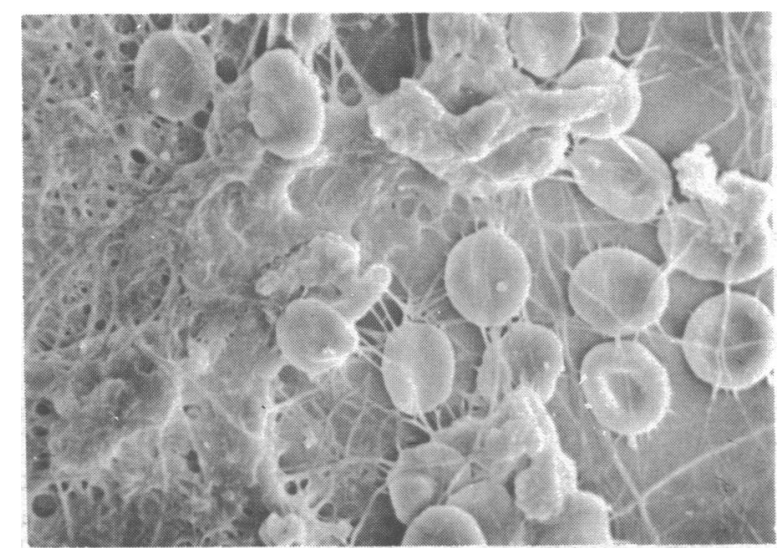

FIG. 2-Scanning electronmicrograph $(\times 1,000)$ of deposit found on PT 325 cuprophane membranes of Gambro-Alwall dialyser after use. Fibrin-like strands are seen trapping red blood cells; platelets are also in evidence.

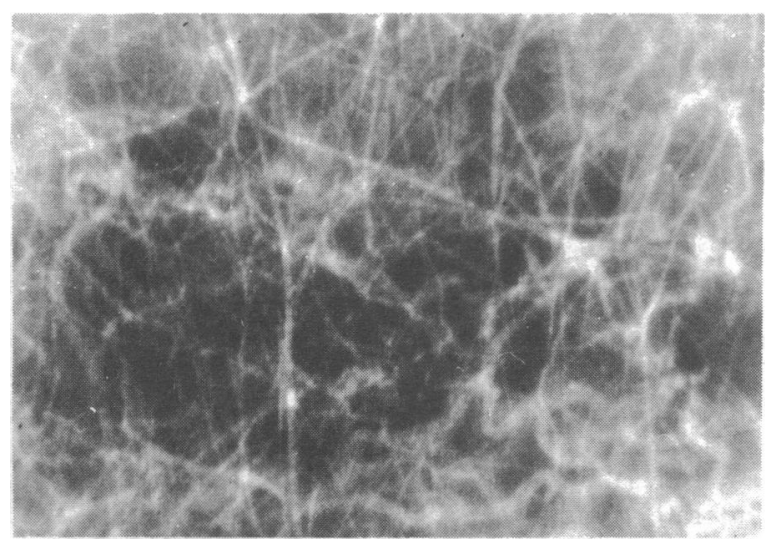

FIG. 3-Incident fluorescence seen when examining used PT 325 cuprophane membranes (from a Gambro-Alwall dialyser) after incubation with fluorescein isothiocyanate conjugated rabbit antihuman fibrinogen. The fluorescence suggests that the strands seen in Figure 2 are fibrin. $(\times 500$.)

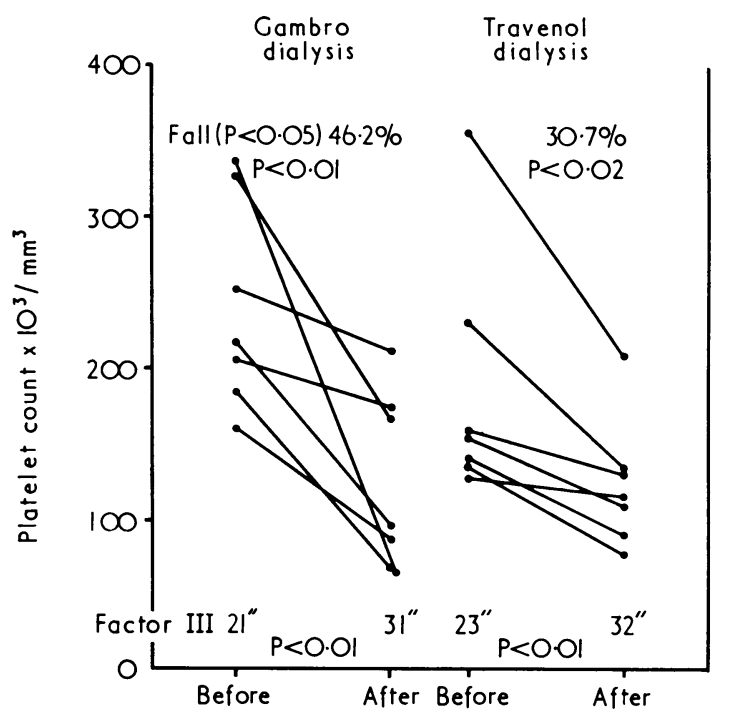

FIG. 4-Platelet counts and platelet factor III clotting times before and after dialysis from Gambro-Alwall and Travenol coil dialyses.

$46 \%$, compared to $31 \%$ after the coil dialyser $(P<0.05)$. The platelet-rich plasma platelet counts followed the pattern of the whole blood platelet counts. As shown in Fig. 4 there was a significant decrease in the mean platelet factor III activity after dialysis by both systems $(P<0.01)$; this was probably due to the decrease in platelet count.

Coagulation Studies.-In all instances the postdialysis thrombin clotting times were restored to the predialysis values, indicating that circulating heparin had been neutralized by the protamine sulphate. After Gambro-Alwall dialyses a shortening of the partial thromboplastin time from an initial mean value of 77 seconds to 65 seconds was noted $(P<0.05)$. This did not occur after Travenol dialysis. There were no changes in the onestage prothrombin time, the kaolin-cephalin clotting time, or the plasma recalcification time after dialysis. There was a significant increase in factor $\mathrm{V}$ activity after both forms of dialysis. The mean pre-Travenol value of $128 \%$ rose to $167 \%$ $(P<0.05)$ and the mean pre-Gambro value rose from $125 \%$ to $177 \%(P<0.02)$. There were variable and non-significant changes in the factor VIII and fibrinogen levels of individual patients over the course of dialysis.

Fibrinolytic Studies.-As seen in Fig. 5 there was a significant fall in plasminogen after Gambro-Alwall dialysis $(P<0.02)$ but not after a Travenol dialysis. There were no significant changes in the euglobulin lysis-time, urokinase sensitivity test, or in the levels of fibrin-fibrinogen degradation products after either form of dialysis.

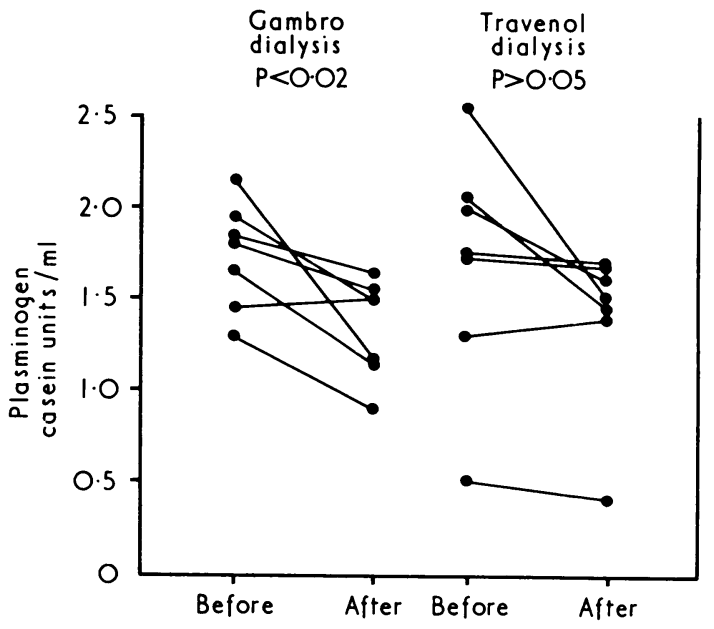

FIG. 5-Plasminogen levels before and after dialysis from Gambro-Alwall and Travenol coil dialyses. 
Radiochromium Platelet Study.-The measured numbers of platelets on the dialysis membranes are shown in the Table where they are compared with the expected platelet loss as based on a dialyser blood loss of $36 \mathrm{ml}$. The number of platelets lost is greatly in excess of that attributable to the whole blood residual volume, suggesting that the platelets are retained preferentially by dialysis membranes.

Comparison of the Number of Platelets Actually Retained on the GambroAlwall Dialysis Membranes After Use, Estimated by using ${ }^{51}$ Cr-labelled Platelets, and the Number of Platelets Assumed to Lie in the Dialyser as Part of a 36-ml Whole Blood Loss

\begin{tabular}{|c|c|c|c|}
\hline & \multirow{2}{*}{$\begin{array}{l}\text { Study } \\
\text { No. }\end{array}$} & \multicolumn{2}{|c|}{ Platelets Retained on Gambro-Alwall Membranes } \\
\hline & & $\begin{array}{l}\text { No. Measured by } \\
{ }^{5 i} \mathrm{Cr} \text { Technique }\end{array}$ & $\begin{array}{c}\text { No. Assumed on } \\
\text { Basis of 36-ml Blood loss }\end{array}$ \\
\hline $\begin{array}{l}1 \\
2 \\
3 \\
4 \\
5\end{array}$ & $\begin{array}{l}\cdots \\
\cdots \\
\cdots \\
\cdots\end{array}$ & $\begin{array}{r}184 \times 109 \\
42.4 \times 109 \\
43.4 \times 109 \\
59.9 \times 109 \\
52.7 \times 109\end{array}$ & $\begin{array}{l}3.9 \times 109 \\
6.4 \times 109 \\
6 \cdot 7 \times 109 \\
7 \cdot 1 \times 109 \\
8.4 \times 109\end{array}$ \\
\hline
\end{tabular}

\section{Discussion}

The most striking change observed in these studies was the large fall in platelet count, which occurred after dialysis by both systems (Fig. 4). This postdialysis fall in platelet count does not appear to have been previously recorded, indeed Larsson (1971) found no change in the platelet count after GambroAlwall dialyses and Hesse et al., (1970) similarly observed no change after Travenol dialyses. It must be noted, however, that in these studies the second specimens were taken at least 18 hours after dialysis. Furthermore, Anderson and De Palma (1966) found no drop in the platelet count of patients after 16 hours of Kiil dialysis. A large drop in platelet count was, however, noted by Mason et al., (1972) when fresh blood ran over dialysis membranes using an ex-vivo test cell system. The platelet count fall was significantly greater over the course of a Gambro-Alwall dialysis than over a Travenol Ultra-Flo 100 coil dialysis. The ${ }^{51} \mathrm{Cr}$-labelled platelet studies (see Table) suggest that the drop in platelet count is secondary to platelet retention in the dialysis membranes.

The evidence provided by the appearance of the dialyser, scanning electronmicrographs, and by fluorescein-labelled antifibrinogen serum (Fig. 3), suggests that platelet-fibrin thrombus is deposited on the membranes of the Gambro-Alwall dialyser. In contrast, this process occurs only to a minor extent when the coil dialyser is used, even though the platelet count is reduced by $30 \%$ after this type of dialysis. It appears that platelets adhere to the dialysis membranes and that, in certain circumstances, th is process may be accompanied by fibrin formation despite the presence of circulating heparin. Other workers have studied thrombus formation on materials used in cardiovascular surgery-for example, Teflon and Silastic-and also suggest that platelet retention to these materials is an important step in thrombus formation (Lyman et $a^{7}$., 1968; Lyman et al., 1969; Rodman and Mason, 1970a, 1970b). Indeed, Salzman (1971) stated "It is now customary to view surface-induced thrombosis as chiefly, if not exclusively, a platelet problem." It is likely that secondary factors such as the blood linear velocity are important in allowing the platelet reaction to proceed to fibrin formation. W. M. Muir (personal communication) noted that when heparinized blood flowing over cellulose-based membranes attains a linear velocity below $5 \mathrm{~cm} / \mathrm{sec}$ thrombus formation is likely to occur. During normal clinical usage the linear velocity of blood flowing through the Gambro-Alwall dialyser is always below this level, whereas higher linear velocities $(5-10 \mathrm{~cm} / \mathrm{sec})$ occur with the Travenol coil. It is possible that the high linear blood velocity through the coil prevents fibrin formation on its membranes. The difference in the linear blood velocities has already been suggested as an explanation for the different blood losses caused by these two dialysers (Muir et al., 1970).
It was of interest to find that platelet and fibrin deposition could occur on dialysis membranes even in the presence of sufficient heparin to prolong the whole blood clotting to more than 30 minutes. This concentration of heparin would be expected to inhibit the action of thrombin on fibrinogen. Platelets are known to have clot-promoting effects on the intrinsic coagulation pathways as well as possessing a component which inhibits heparin, known as platelet factor IV (Godal, 1962). It is possible that sufficient thrombin is generated within the platelet micro-environment to clot fibrinogen. Alternatively, the fibrin strands may have been formed as a result of enzymes other than thrombin or even by non-enzymetic means. The fact that fibrin-like material can be deposited in the vicinity of platelets even in the presence of heparin has important implications in the study of arterial thrombosis where the conventional anticoagulants do not play a large part in prevention or treatment.

The postdialysis rise in factor $\mathrm{V}$ activity, together with a shortening of the partial thromboplastin time, may indicate activation of the patient's coagulation mechanism. Similar findings have also been recorded by Mason et al., (1972) who observed a fall in the partial thromboplastin time when blood came in contact with dialysis membranes in an ex-vivo test cell system and by Larsson (1971) who noted a rise in factor V activity together with increases in factor VIII and fibrinogen levels the day after a Gambro-Alwall dialysis. Larsson (1971), however, could not find increased fibrinolytic activity after dialysis, indeed he found an increase in the level of urokinase inhibitors on the day after dialysis. Our results, however, show a significant fall in the plasminogen level immediately after a GambroAlwall dialysis (Fig. 5), which may reflect increased plasminogen activation secondary to the fibrin formation occurring in the dialyser.

The haemostatic changes during dialysis and the thrombus deposition on the dialysis membranes which we have observed are similar in many respects to the changes occurring during cardiopulmonary bypass surgery. A decrease in platelet count and plasminogen level has been observed among other changes in the blood coagulation factors of patients undergoing such surgery (Salzman and Britten, 1965), and fibrin formation within the extracorporeal circuit of the cardiopulmonary bypass is common.

In conclusion, we have observed haemostatic changesnamely, falls in the platelet count and plasminogen levels and a rise in factor $\mathrm{V}$ levels -in patients undergoing dialysis by the Gambro-Alwall dialyser, which would appear to be associated with the formation of thrombus on the membranes of that dialyser. These changes occur in spite of adequate heparin anticoagulation and may lead to an undesirably high blood loss for the regular dialysis patient. Our study suggests that platelet retention by the dialysis membranes may be an important early step in the reaction which proceeds to fibrin formation. Further studies on the effect of antiplatelet agents and different types of dialysis membranes in reducing dialyser thrombus formations are in progress.

We wish to thank Mrs. A. Sandiford, Miss E. Martin, and Miss J. Grant, of the Coagulation Unit, Department of Medicine, Glasgow Royal Infirmary, Mr. Ian Howe, of the Blood Transfusion Unit, Glasgow Royal Infirmary, and Miss R. Wilkinson, of the Bioengineering Unit, University of Strathclyde, for their expert technical help. We also thank Professor A. C. Kennedy for his critical help in this study and for allowing us to investigate patients under his care.

This study was supported by a grant from $\mathrm{Ab}$ Gambro (Lund, Sweden); this is gratefully acknowledged. Dr. C. R. M. Prentice also acknowledges his grant from the Wellcome Trust.

\section{References}

Anderson, C. F., and De Palma, J. R. (1966). Transactions American Society for Artificial Internal Organs, 7, 210.

Breckenridge, R. T., and Ratnoff, O. D. (1962). Blood, 20, 137

Brunner, F. P., Gurland, H. J., Härlen, H., Parsons, F. M., and Schaerer, K. (1972). Proceedings of the European Dialysis and Transplant Association. In press. 
Dacie, J. V., and Lewis, S. M. (1970a). In Practical Haematology, 4th edn., p. 70. London, Churchill.

Dacie, J. V., and Lewis, S. M. (1970b). In Practical Haematology, 4th edn., p. 326. London, Churchill.

Douglas, A. S. (1964). In Anticoagulant Therapy, p. 279. Oxford, Blackwell Scientific.

Godal, H. C. (1962). Scandinavian fournal of Clinical and Laboratory Investigation, 14, 223.

Hardisty, R. M., and Hutton, R. A. (1965). British fournal of Haematology, $11,258$.

Hesse, V. E., Mink, I. B., Murphy, G. P., Moore, R. H., and Ambrus, J. L. (1970). New York fournal of Medicine, 70, 1851

Hocken, A. G., and Marwah, P. K. (1971). Lancet, 1, 164

Langdell, R. D., Wagner, R. U., and Brinkhous, K. M. (1963). Fournal of Laboratory and Clinical Medicine, 41, 637.

Larsson, S. O. (1971). Scandinavian fournal of Haematology, Suppl. No. 15, p. 1 .

Lawson, D. H., Will, G., Boddy, K., and Linton, A. L. (1968). Proceedings of the European Dialysis and Transplant Association, 5, 167.

Lindsay, R. M., et al., (1972). Clinical Nephrology. In press.

Lyman, D. J., Brash, J. L., Chaikin, S. W., Klein, K. G., and Carini, M. (1968). Transactions. American Society for Artificial Internal Organs, 14, 250.

Lyman, D. J., Brash, J. L., and Klein, K. G. (1969). Proceedings of the Artificial Heart Program Conference, $1,113$.

Mason, R. G., Shermer, R. W., and Zucker, W. H. (1972). Transactions. American Society for Artificial Internal Organs, 18, 32.
McNicol, G. P., Barakat, A. A., and Douglas, A. S. (1965). Scottish Medical fournal, 10, 189

McNicol, G. P., and Douglas, A. S. (1964). In Recent Advances in Clinical Pathology, ed. S. C. Dyke, p. 187. London, Churchill.

Merskey, C., Kleiner, G. J., and Johnson, A. J. (1966). Blood, 28, 1.

Muir, W. M., Lindsay, R. M., and Davidson, J. F. (1970). Proceedings of the European Dialysis and Transplant Association, 769.

Mylon, E., Winternitz, M. C., and de Süto-Nagy, G. T. (1942). fournal of Biological Chemistry, 143, 21.

Nilsson, I. M., and Olow, B. (1962). Acta Chirurgica Scandinavia, 123, 247.

Proctor, R. R., and Rapaport, S. I. (1961). American fournal of Clinical Pathology, 36, 212.

Ratnoff, O. D., and Menzie, C. (1964). In Blood Coagulation, Hemorrhage and Thrombosis, ed. L. M. Tocantins and L. A. Kazal, p. 224. New York, Grune and Stratton.

Remmert, L. F., and Cohen, P. P. (1949). Journal of Biological Chemistry, 187,431 .

Rodman, N. F., and Mason, R. G. (1970a). Thrombosis et Diathesis Haemorrhagica, Suppl. No. 40, p. 145.

Rodman, N. F., and Mason, R. G. (1970b). Thrombosis et Diathesis Haemorrhagica, Suppl. No. 42 , p. 61 .

Salzman, E. W., and Britten, M. B. (1965). In Haemorrhage and Thrombosis, p. 133, London, Churchill.

Salzman, E. W. (1971). Federation Proceedings, 30, 1705.

Shanberge, J. N., Matsuoka, T., and Fukui, H. (1967). American fournal of Clinical Pathology, 47, 533.

\title{
Comparative Evaluation of Water Recovery Test and Fluoroscopic Screening in Positioning a Nasogastric Tube during Gastric Secretory Studies
}

\author{
J. M. FINDLAY, R. J. PRESCOTT, W. SIRCUS
}

British Medical fournal, 1972, 4, 458-461

\section{Summary}

Acid secretion studies were carried out in $\mathbf{5 0}$ patients. Fluoroscopy or a modified water recovery test was used to position the nasogastric tube. For every patient each positioning procedure was used on one of two consecutive days, and acid output studies were performed. The tests were assessed by two observers and accepted or rejected. Analysis revealed no significant differences between the acid studies irrespective of the method used for positioning the nasogastric tube. Rejection rates by either procedure showed no significant difference. Practical considerations favour the continued use of water recovery as a means of positioning the nasogastric tube for gastric secretion studies.

\section{Introduction}

Two methods are investigated for positioning the nasogastric tube in patients undergoing tests of gastric secretion. Radiological, recommended by several groups (Levin et al, 1948; Johnston and McCraw, 1958; Marks, 1961; Baron, 1963) and an alternative, the water recovery test. With phenol red as a marker the recovery of $85-87 \%$ of swallowed water suggested that fluoroscopy may be unnecessary (Hassan and Hobsley, 1970).

The present study was designed to examine a modified water recovery test, and to compare and contrast it with the use of fluoroscopy.

Gastrointestinal Unit, Western General Hospital, Edinburgh J. M. FINDLAY, M.R.C.P., D.M.R.D., Senior Registrar in Medicine W. SIRCUS, M.D., F.R.C.P., Consultant Physician

Department of Social Medicine, University of Edinburgh R. J. PRESCOTT, M.SC., PH.D., Lecturer

\section{Patients and Methods}

Fifty patients were studied. None had undergone gastric surgery. They had a variety of upper-gastrointestinal disorders, and the determination of the gastric secretory response to pentagastrin was in the course of routine clinical investigations.

The patients were allocated to two groups using a procedure sequence determined by random selection from a pack of playing cards. Thus, 25 patients were allocated to each of the two groups-group $A$ with odd numbers and group $B$ with even numbers.

Standard Water Recovery Test.-A nasogastric tube (14 F. G. Levine $x$-ray opaque) was measured from the nose to a point $5 \mathrm{~cm}$ above the umbilicus by applying the tube to the body contour and by appropriate marking. The tube was then passed through the nose to this mark and aspiration was attempted. If unsuccessful, the tube position was adjusted until aspirate was obtained. Aspiration was then completed. The patient now drank $20 \mathrm{ml}$ of water and lay in a semirecumbent position on the left side. If between 16 and 20 $\mathrm{ml}$ of water could then be recovered by using manual aspiration with a syringe the position of the tube was regarded as satisfactory. If not, the patient was first turned supine and then into the right lateral position. If adequate recovery was still not achieved the tube was withdrawn in $2.5-\mathrm{cm}$ stages, and was regarded as being in satisfactory position when 16 to $20 \mathrm{ml}$ were recovered in toto.

\section{PROCEDURE}

Group A.-A "standard water recovery test" was performed. When a satisfactory tube position had been achieved the tube was secured to the nose with adhesive tape. The patient then went to the $x$-ray department. A plain radiograph of the abdomen was taken and the patient returned to the laboratory for the ensuing acid output test. No information regarding 